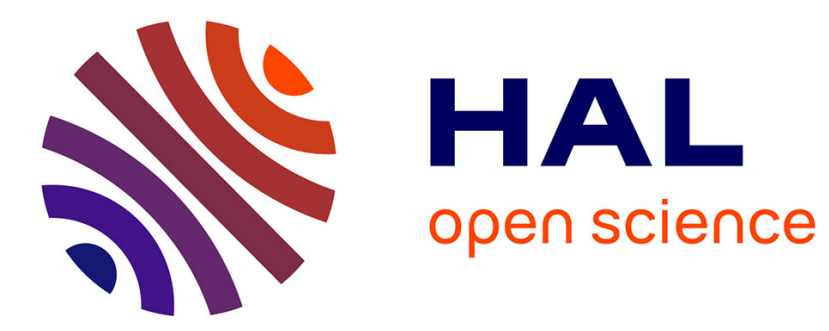

\title{
Compact diversity antenna for UHF RFID readers
}

\author{
B. Ouattara, C. Hamouda, B. Poussot, Jean-Marc Laheurte
}

\section{To cite this version:}

B. Ouattara, C. Hamouda, B. Poussot, Jean-Marc Laheurte. Compact diversity antenna for UHF RFID readers. Electronics Letters, 2012, 48 (16), pp.975-977. hal-00767400

\section{HAL Id: hal-00767400 https://hal.science/hal-00767400}

Submitted on 20 Dec 2012

HAL is a multi-disciplinary open access archive for the deposit and dissemination of scientific research documents, whether they are published or not. The documents may come from teaching and research institutions in France or abroad, or from public or private research centers.
L'archive ouverte pluridisciplinaire HAL, est destinée au dépôt et à la diffusion de documents scientifiques de niveau recherche, publiés ou non, émanant des établissements d'enseignement et de recherche français ou étrangers, des laboratoires publics ou privés. 


\section{Compact diversity antenna for UHF RFID readers}

\section{Y.B. Ouattara, C. Hamouda, B. Poussot and J.M. Laheurte}

A diversity antenna combining four inverted-F antennas (IFAs) is evaluated for UHF RF identification (RFID) readers. Polarisation and pattern diversities are obtained for a sequentially rotated configuration of the IFAs. Mutual coupling between ports is minimised by etching quarter-wavelength slots into the ground plane. The resulting envelope correlation coefficient is less than 0.003 in the working band. A switching diversity scheme is then applied to evaluate the tags readability in a lab environment. It is shown that the antenna diversity enhances the reading range compared to a circularly or a linearly polarised antenna of the same size.

Introduction: One of the major problems facing RFID systems today is to increase the tag identification rates when a large number of tags is present in a small enclosure. The main cause for missed tags is the coupling between adjacent tags. Tag coupling yields what is sometimes called 'masking', but the antenna community will rather visualise it like a pattern distortion and a voltage drop at the antenna input. Under these conditions, the voltage at the chip input remains below the threshold, the tag cannot modulate the backscattered signal and cannot be identified by the reader. In addition, RFID communications normally take place in multipath environments and could suffer from large signal fadings which also reduce the identification rate.

On the other hand, it is well known that multi-element antennas (MEAs) and diversity techniques overcome the multipath fading and signal depolarisation problems $[1,2]$. RFID readers usually integrate two or four output channels to allow some antenna multiplexing, i.e. antenna diversity with a switched combining scheme. But most of the time, RFID system integrators use cumbersome commercially antennas and distribute them over a large area around the region to scan

In this Letter, we propose a new reader antenna built around four sequentially rotated IFAs and a diversity scheme. The diversity antenna is characterised in terms of S-parameters, envelope correlation coefficient $\rho \mathrm{e}$, polarisation and radiation patterns in the European UHF RFID band $(865 \mathrm{MHz}-868 \mathrm{MHz})$. Tags readability is measured for 38 passive tags packed in a cardboard box, first with the diversity antenna, then with commercial circular and linear polarised antennas.

Antenna design: The layout of the proposed structure is depicted in Fig. 1 including the IFA elements, the ground plane and the reflector occupying a total volume of $30 \times 30 \times 5 \mathrm{~cm}$. All of them are made up of copper material. The IFAs are mounted on the ground plane with a $90^{\circ}$ sequential rotation between them [3]. IFA ports are fed through four coaxial cables. A reflector is used to reduce the back radiation of the antenna and placed $2 \mathrm{~cm}$ below the ground plane. To isolate the IFA ports, $\lambda \mathrm{o} / 4$ slots $(\lambda \mathrm{o} \sim 34.6 \mathrm{~cm})$ are etched in the half-length of the ground plane [4]. Slots modify the current flow on the ground plane and confine it around the slots boundaries $[5,6]$. The structure is simulated using the commercial electromagnetic solver High Frequency Structure Simulator (HFSS).

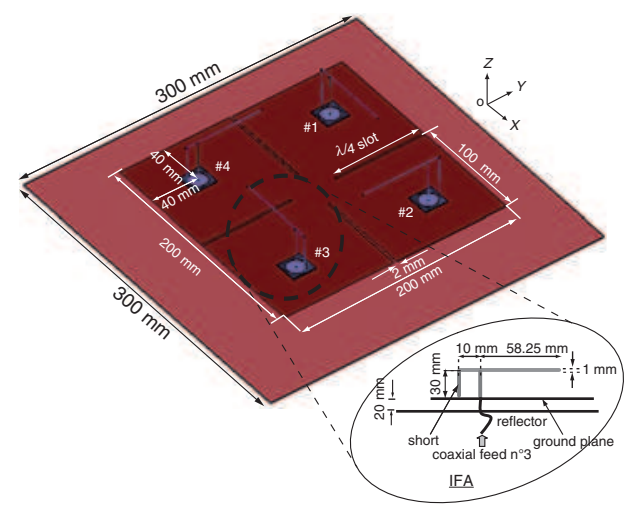

Fig. 1 Top view of diversity antenna

Antenna simulation and measurement: Simulated and measured S-parameters are plotted in Fig. 2, where IFAs are labelled as in
Fig. 1. The reflection coefficients (Sii) are lower than $-20 \mathrm{~dB}$ at the centre frequency $868 \mathrm{MHz}$ with a $5.2 \%$ bandwidth ( $\mathrm{Sii} \geq-8 \mathrm{~dB}$ without slots). Low mutual coupling between orthogonal (S12< $-12 \mathrm{~dB})$ and collinear $(\mathrm{S} 13<-20 \mathrm{~dB})$ IFAs are obtained in the entire band with the slotted ground plane. The $40 \mathrm{MHz}$ shift in the measured and simulated S13 could be attributed to the cable currents which are not modelled in the HFSS simulation. The fields radiated by these currents result in additional coupling between ports 1 and 3. Measured patterns of the antenna in Fig. 3 indicate a $5 \mathrm{dBi}$ IFA gain and a minimum front-to-back ratio of 10dBi. By adding the reflector backing, the gain is increased by $1 \mathrm{~dB}$ for each IFA while the back radiation is reduced by more than $5 \mathrm{~dB}$.

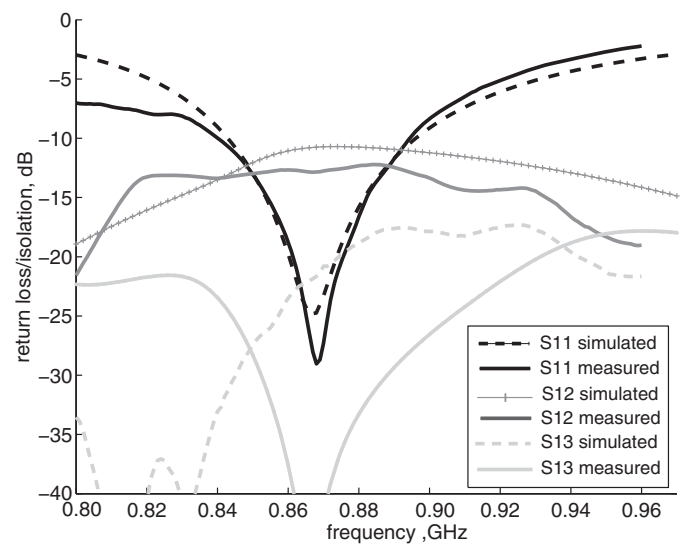

Fig. 2 Reflection coefficient (Sii) and mutual coupling (Sij)



Fig. 3 Polarisation diversity: simulated radiation patterns $E_{\theta}$ and $E_{\varphi}$ in yoz-plane

$-E_{\theta}$

Diversity performance: Fig. 3 shows the angular distributions of the electric field $\mathrm{E}_{\theta}$ and $\mathrm{E}_{\varphi}$ for each IFA in the yoz-plane $\left(\varphi=0^{\circ}\right)$. The $\mathrm{E}_{\theta}$ null for IFA 2 at $+30^{\circ}$ is compensated by a maximum $\mathrm{E}_{\theta}$ for IFA 4 and vice-versa for $-30^{\circ}$ by symmetry of revolution. IFA 1 and IFA 3 exhibit important $\mathrm{E}_{\varphi}$ values with maxima directed towards $-30^{\circ}$ and $+30^{\circ}$, respectively, while IFA 2 and IFA 4 are characterised by very weak IFA levels. The simulated radiation patterns $10 \log \left(\mathrm{E}_{\theta}^{2}+E_{\varphi}^{2}\right)$ of IFA 1 and IFA 3 focus their maximum gain respectively in $\pm 30^{\circ}$ in the elevation plane. The same complementarity of gain orientation is observed for IFA 2 and IFA 4. On the other hand, the envelope correlation coefficient has been calculated using the measured S-parameters [7]. In the working band, we find $\rho \mathrm{e}<0.003$ both between the collinear and the orthogonal IFAs. All these results confirm the potentialities of the structure in terms of pattern and polarisation diversities.

Tags readability test: The readability test makes use of 38 passive tags built around meandered dipoles. Each tag is stuck on a small plastic box $(4 \times 4 \times 7 \mathrm{~cm})$. Then, the 38 tags are randomly placed into a rectangular cardboard box. The test zone is a pie slice of $3 \mathrm{~m}$ radius and curvature sector varying from $-40^{\circ}$ to $+40^{\circ}$. The reading rate is evaluated 
against the distance between the cardboard box and the reader's antenna and its azimutal angle from the antenna centre. The cardboard box is then moved in the test zone using $10 \mathrm{~cm}$ radial steps and $10^{\circ}$ angular steps (270 measurement samples). The measurements were made in a lab room dominated by the presence of numerous metallic objects (cabinets, measurement equipment) and concrete walls. The cardboard box and the reader antennas are placed $1.1 \mathrm{~m}$ above the ground floor. Each of the four IFA ports are connected through coaxial cables to one of the four output channels of the RFID reader Impinj's Speedway R420 [8]. The reader then sequentially switches between the IFAs. In a commercial version, the antenna should be fed by a SP4T connected to one of the reader outputs. The reader delivers $29 \mathrm{dBm}$ to each IFA element which results in a EIRP (equivalent isotropic radiated power) of $29 \mathrm{dBm}+5 \mathrm{~dB}=34 \mathrm{dBm}$. The tags readability with the diversity antenna is compared with a $7 \mathrm{dBic}$ circularly-polarised antenna (Poynting PATCH-A0025 $24.5 \times 23.5 \times 4 \mathrm{~cm}$ ) and a $5 \mathrm{dBi}$ linearly polarised antenna (IMPINJ-A0311-USA $46 \times 9 \times 2 \mathrm{~cm}$ ). For a fair comparison, reader output powers are adjusted so that identical EIRPs are obtained for each antenna.

Fig. 4 shows the rate of tag readability in the test zone for the three reader antennas: diversity antenna (Fig. 4a), CP antenna (Fig. 4b) and LP antenna (Fig. 4c). As shown in Fig. 4a, 100\% of the tags have been read by the diversity antenna up to 1.5 metres. Beyond this distance, the rate of tags readability remains above $70 \%$ in the measurement area. When the reader is connected to the $\mathrm{CP}$ antenna the $100 \%$ reading range is shorter, about 1 metre (Fig. $4 b$ ). This readability rate decreases when the cardboard box moves away from the reader. With the CP antenna only $10 \%$ of the tags are read at 2 metres compared with more than $80 \%$ with the diversity antenna. Unlike the two other antennas, a fluctuation of tags reading with distance is observed for the LP antenna, as illustrated in Fig. $4 c$. Two hot zones where $80 \%$ of the tags can be read are identified: the first is below 0.70 from the reader and the second at approximately 2 metres. The reading rate does not exceed $40 \%$ elsewhere. The second reading spot at 2 metres is attributed to multipath in-phase combination. These fluctuations are not observed with the diversity antenna where the tag readability rate decreases continuously along the distance. In any case, the reading rate is much larger for the diversity antenna than the two others.



Conclusion: A compact diversity antenna is developed to enhance the readability for a strong density of passive UHF tags in indoor scenarios. By combining space, pattern and polarisation diversities, the proposed antenna offers better reading rates than available commercial RFID reader antennas for equivalent volumes. Associated to an integrated SP4T, and added to classical RFID techniques for reading improvement such as the displacement of the tagged objects and/or the multiplexing of several reader antennas at distant points, the proposed antenna should make possible a convergence to a $100 \%$ reading rate much faster than the existing antenna solutions.

(C) The Institution of Engineering and Technology 2012 8 June 2012

doi: 10.1049/el.2012.1805

One or more of the Figures in this Letter are available in colour online.

Y.B. Ouattara, C. Hamouda, B. Poussot and J.M. Laheurte (Laboratoire ESYCOM, Université Paris-Est Marne-la-Vallée, Bâtiment Copernic, 5 boulevard Descartes, Champs-sur-Marne 77454, Marne-la-vallée, Cedex 2, France)

E-mail: ouattara@univ-mlv.fr

\section{References}

1 Vaughan, R., and Andersen, J.B.: 'Channel, propagation and antennas for mobile communications' (IEE, London, UK, 2003)

2 Decroze, C., Carsenat, D., Mouhamadou, M., Tounou, C., Reynaud, S., and Monediere, T.: 'Measurement of antenna diversity performances on a compact wireless device, in real environment'. IEEE Antennas and Propagation Int. Symp., San Diego, CA, USA, 2008

3 Kim, J.-S., Shin, K.-H., Park, S.-H., Choi, W.-K., and Seong, N.-S.: 'Polarization and space diversity using using inverted-F antennas for RFID reader applications', IEEE Antennas Wirel. Propag. Lett., 2006, 5, pp. 265-268

4 Andrenko, A., Andrenko, S., and Yamagajo, T.: 'Novel design for reducing mutual coupling and signal correlation in diversity handset antennas'. IEEE Asia Pacific Microwave Conf. Proc., (APMC), Yokohama, Japan, 2010

5 Karaboikis, M., and Soras, C.: 'Compact dual-printed inverted-F antenna diversity systems for portable wireless devices', IEEE Antennas Wirel. Propag. Lett, 2004, 3, pp. 9-14

6 Alves, T., Poussot, B., and Laheurte, J.M.: 'PIFA-top-loaded-monopole antenna with diversity features for WBAN applications', IEEE Antennas Wirel. Propag. Lett, 2011, 10, pp. 693-696

7 Blanch, S., Romeu, J., and Corbella, I.: 'Exact representation of antenna system diversity performance from input parameter description', Electron. Lett., 2003, 39, pp. 705-707

8 http://www.cisper.nl/rfid/products/readers/

Fig. 4 Tags readability test

$a$ Diversity antenna

$b$ CP antenna

$c$ LP antenna 